T. Dorn; J.C. Yzermans; P.M. Spreeuwenberg; J. van der Zee.

Physical and mental health problems in parents of adolescents with burns--a controlled, longitudinal study Journalof psychosomatic Research 2007 , vol. 63, nr. 4 p. 381-389.

\begin{tabular}{|l|l|}
\hline Postprint Version & 1.0 \\
Journal website & $\underline{\text { http://dx.doi.org/10.1016/j.jpsychores.2007.02.005 }}$ \\
\hline Pubmed link & $\underline{\text { http://www.ncbi.nlm.nih.gov/sites/entrez?Db=pubmed\&Cmd=ShowDetailView }}$ \\
\hline $\begin{array}{l}\text { \&TermToSearch=17905046\&ordinalpos=1\&itool=EntrezSystem2.PEntrez.Pubm } \\
\text { ed.Pubmed_ResultsPanel.Pubmed_RVDocSum }\end{array}$ \\
\hline DOI & $\underline{10.1016 / \text { j.jpsychores.2007.02.005 }}$
\end{tabular}

This is a NIVEL certified Post Print, more info at http://www.nivel.eu

\title{
Physical and mental health problems in parents of adolescents with burns - a controlled, longitudinal study
}

\author{
Tina Dorn, JoRis C. YZermans, PETER M. SPREEUWENBERG AND JoUKE VAN DER ZEE \\ Netherlands Institute for Health Services Research (NIVEL), Utrecht, The Netherlands \\ Received 4 October 2006; revised 22 January 2007; accepted 6 February 2007. Available online 29 \\ September 2007.
}

\begin{abstract}
Objective: Caregiving has been described in the literature as a risk factor for ill health in the carer. This controlled, prospective study examines the course of physical and mental health problems in parents of adolescent survivors of a mass burn incident.

Methods: Health information was extracted from electronic medical records. Continuous data were available for 1 year before and 4 years after the fire. Cohorts comprised 273 parents of survivors with burns, 199 parents of survivors without burns, and 1756 controls. Post-fire increases in health problems were compared by means of logistic regression.

Results: Parents of burn victims were more likely to present mental health problems during the first 2 years after the incident, when compared to the baseline. Moreover, they were more likely to present cardiovascular health problems in every year following the disaster, compared to the baseline. Increases observed in mental and cardiovascular health problems were significantly larger in parents of burn victims compared to controls. Risk factors for presenting mental health problems were female gender of the parent and a large burn size in the child. Lower socioeconomic status and female gender of the parent predicted cardiovascular health problems.
\end{abstract}

Conclusion: Evidence gained in longitudinal studies informs on which health problems are most likely to develop in parental caregivers. In the interest of both parent and child, a familyoriented approach is proposed.

\section{INTRODUCTION}

The literature on pediatric chronic illness supports the idea that caring for a medically fragile child or adolescent has implications for the health of parents [1]. There are various examples of empirical investigations on the impact of childhood illness on the family, encompassing conditions such as cerebral palsy [2] and [3], physical disabilities [4] and [5], or sickle cell disease [6]. A large body of research is available on parents of children with cancer. This literature indicates that distress reactions such as anxiety or depression are common in affected parents [7].

Although several studies on the mental health of parental caregivers exist, there has been little investigation of physical health outcomes [8] and [9]. There is a long tradition of studying physical health 
outcomes in elderly caregivers (e.g., Refs. [10] and [11]), but less is known on middle-aged parents who are caregivers of their children.

The current study deals with mental and physical health outcomes of parents of children with burns. As in other families with chronically ill children, the burden of care generally falls upon parents who attempt to balance the burn victim's health care needs with those of other family members and work commitments [12]. Follow-up care can be very time-consuming and painful for the patient. Procedures may include daily baths, dressing changes, exercises, and wearing of splints and pressure garments [13]. Next to the caretaking role, parents must also resume family roles such as spouse, parent of the patient's siblings, housekeeper, cook, and many others. A look into the literature shows that studies on parents of burn victims are generally scarce. As in the research on other childhood diseases, mental health problems in parents (i.e., depression, anxiety, posttraumatic stress symptoms) are more often the subject of investigation, when compared to physical health problems. With regard to mental health problems, the conclusions drawn in the literature are inconsistent. While most studies on parents of burn patients report adverse mental health outcomes [14], [15], [16], [17], [18], [19], [20] and [21], some do not demonstrate adverse effects [12] and [22]. Regarding physical health problems, to our knowledge, there exists only one publication examining physical health consequences in family members of burn patients. It demonstrated that immune function in spouses and parents of burn patients was suppressed $72 \mathrm{~h}$ after the admission of the burn patient and improved 2-5 weeks later, thus only indicating short-term effects [14]. Besides the lack of physical outcome measures, there are also some methodological concerns regarding the existing research on parents of burn victims. Samples are often small, drawn from specialty centers, and it is unclear whether parents who cope well are appropriately represented among the respondents. Finally, most studies are crosssectional in design and lack preburn assessments, rendering causal inferences difficult.

The current population-based, prospective study tries to tackle some of these shortcomings. It aims at examining both physical and mental health outcomes in parents of adolescent burn victims, using data extracted from electronic medical records. The adolescents themselves were injured in a fire, which occurred in an overcrowded pub in Volendam, the Netherlands, on January 1, 2001. The fire broke out around midnight as hundreds of young revelers were toasting the New Year. As a result, 14 young people lost their lives, and about 240 were injured [23].

The purpose of the present study is to study physical and mental health outcomes in the parents of these adolescents during a period of 4 years after the incident. Their outcomes are compared to those of other parents, using pre- and postevent data. In addition, gender, size of burn, socioeconomic characteristics of the family, and the number of children in the family who have been involved in the burn incident will be investigated as risk factors. Gender is of special interest since women traditionally have a caretaking role and often attempt to balance family members' needs. For this reason, women are assumed to be more vulnerable to stress within the family than men [24]. Female gender as a risk factor has not been examined extensively, however, which is due to the fact that fathers are largely underrepresented in the existing research on parents of burn victims. The inclusion of socioeconomic characteristics seems logical as well, since lower socioeconomic status in general is associated with more ill health than higher socioeconomic status [25]. In addition, it is expected that effects in parents of children with burns will vary with the size of the burn. The total burned surface area of the child can be considered to be one of the most important injury characteristics, and it is directly related to the rehabilitation efforts a child and his family have to undergo.

Specifically, the hypotheses of the study can be stated as follows:

1. During follow-up, the proportion of parents presenting with mental and physical health problems significantly increases in parents of adolescents with burns compared to the prefire baseline.

2. The largest postfire increases are seen in parents of adolescents with burns, followed by parents of adolescents who have survived the fire without burns, and increases are smallest in controls.

3. The peak period of mental and physical health effects is observed during the first year after the fire. The share of parents presenting with mental health problems is expected to decline in the course of the years as adaptation occurs over time.

4. Parental mental and physical health problems vary according to the size of the burn of the child and parental socioeconomic status.

5. Mothers of adolescents with burns demonstrate larger increases in mental health and physical health problems than fathers of adolescents with burns. 


\section{METHOD}

\section{Setting}

Volendam is a former fishing town located 20 miles north of Amsterdam and has about 20,000 inhabitants. The community is close-knit, and mobility is low. The population is served by four family practices. In the Netherlands, family practitioners (FPs) have a key position as gatekeepers to specialist care, which is only accessible after referral by a FP. Accordingly, most contacts between the public at large and the health care system take place in family practice ( $\sim 90 \%)$. Dutch FPs have fixed patient lists, and patients are registered with one FP only [26]. Basically, there are no financial barriers for patients to FP care. Until 2006, two types of health insurance existed in the Netherlands, public and private insurance. Patients with an annual income below a specific level were insured through public insurance; above this level, patients were privately insured ( $\sim 40 \%$ of the population). Insurance type can thus be used as an indicator for the socioeconomic status of the patient. The use of electronic registrations is well established in Dutch family practice. In our study, all FPs classified their patients' health problems according to the International Classification of Primary Care (ICPC), an internationally endorsed classification system which is compatible with the International Statistical Classification of Diseases, 10th Revision [27] and [28]. It is divided into several chapters, each dealing with one organ system (e.g., cardiovascular, musculoskeletal, gastrointestinal).

\section{Data protection}

The data for the current study were extracted from the electronic registrations of FPs in an automated way. In the current study, the privacy of patients was protected by making use of patient identification numbers. The extracted data did not contain names or addresses, and individuals could not be personally identified. Patients were invited to object against the use of their data, but no one disagreed. The data collection procedure was approved by the Dutch Data Protection Authority, which supervises the compliance with acts that regulate the use of personal data.

\section{Sampling of cohorts}

As a first step, it was necessary to identify those adolescents who had been present in the bar. According to official estimates, about 350 people were in the building at the time of the fire. The four FP practices were able to identify a total of 335 persons in their registrations (14 deceased adolescents and 321 survivors, with and without physical injuries). Thirty-five of the surviving victims were excluded from the study since they belonged to a practice which was not yet fully computerized. The characteristics of survivors enrolled in the nonparticipating practice $(n=35)$ were compared with those of survivors enrolled with the participating practices ( $\mathrm{n}=286$ ). Survivors included in the final study sample did not significantly differ from nonparticipants with respect to burn size, number of days in hospital, gender, age, or insurance status. Victims with burn injuries had a mean total burn surface area of $14.9 \%$ (S.D. $=17.1$; range, 76\%; median, 8\%) and spent, on average, 34.2 days in hospital during the first 12 months after the disaster (S.D.=59.3; range, 365 days; median, 13.5 days). Victims with burns $(\mathrm{n}=162)$ had a mean age of 16.9 years (S.D.=2.1); victims without burns $(n=124)$ were 17.8 years on average (S.D.=2.9).

As a second step, we identified all cohabiting parents of the victims with the help of the electronic patient registration $(n=499)$. Twenty-seven of these parents were excluded because they had lost a child due to the fire- an experience different from the one we aimed to examine-resulting in a sample of 472 parents (273 parents of burn victims and 199 parents of unburned victims). These 472 parents were distributed among 249 family units. In 28 out of the 249 affected family units included, more than one child had been present during the fire.

As a third step, we selected all parents from the three participating family practices with children aged 1420 years who had not been trapped in the fire. These parents are referred to as "community controls" ( $\mathrm{n}=1756$, distributed among 952 family units).

\section{Assessment of health problems}

The assessment of health problems was based on the electronic patient records of FPs. Mental health problems were defined as problems belonging to the ICPC chapters "psychological" and "social." In addition, physical health problems, as summarized in the ICPC chapters "cardiovascular," "musculoskeletal,” "respiratory,” "gastrointestinal,” and “dermatological,” were analyzed since they capture the most important areas of morbidity. If a patient presented a health problem at least once in a 
given period, the value of the outcome variable was one. Parents who did not contact the FP for the health problem in question in a given period received a count of zero.

Five different time periods were distinguished: the 12-month period prior to the fire (year 2000), 0-12 months post fire (year 2001), 12-24 months post fire (year 2002), 25-36 months post fire (year 2003), and 37-48 months post fire (year 2004).

\section{Analyses}

For the analysis of health problems, logistic regression was used. In the current study, repeated measurements are nested within persons, and persons are nested within couples. In order to account for this dependency of observations, a multilevel modeling approach was chosen [29], based on the MLwiN software package (available at www.cmm.bristol.ac.uk).

The outcome measure in the regression analysis was the presence or absence of a health problem (cardiovascular, musculoskeletal, gastrointestinal, dermatological, respiratory, or mental; coded 1 if present and 0 if absent). The predictors were introduced into the models as follows. The three parent groups (parents of children with burns, parents of children without burns, and controls) were modeled by one dummy each (model without intercept). Interaction terms of group and time (group*year 2001, group*year 2002, group*year 2003, and group*year 2004) were used for modeling the deviation from the year pre fire. All regression model were adjusted for the influence of covariates (age, gender, family practice, and insurance type), which had been centered around their means before introducing them into the equation.

Table 3 reports the results of 6 regression analyses (one for each health problem). These analyses provide two types of information. First, they provide information on within-group comparisons. Second, they inform on between-group comparisons. In Table 3, significant within-group comparisons are printed in bold [presented as odds ratios (ORs) and 95\% confidence intervals (CIs)]. An OR above 1 indicates that, within the group, the likelihood for presenting the health problem was higher than in the year pre fire (the year 2000). An OR below 1 indicates that, within the group, the likelihood for presenting the health problems was lower than in the year pre fire. Between-group comparisons were based on the calculation of contrasts. These contrasts test whether the postfire increase (or decrease) observed in one group is statistically different form the postfire increase (or decrease) seen in another group. If contrasts yielded significant results (alpha $=.05$ ), they were marked with indices (a,b,c; see legend of Table 3).

Table 4 and Table 5 provide the results of two additional regression analyses for which only the data of the parents of children with burns were used. These models examine the influence of risk factors for cardiovascular and mental health problems in parents of burned children. The outcome measure in the analysis reported in Table 4 is mental health problems during the first two years after the fire (if mental health problems were present during at least 1 of the 2 years, the value of the outcome variable was 1 ; if absent, it was 0 ). The outcome measure in the analysis presented in Table 5 is cardiovascular problems during the 4 years post fire (if cardiovascular health problems were present during at least 1 of the 4 years, the value of the outcome variable was 1 ; if absent, it was 0 ). The decision to consider time windows different from the previous analysis was based on the findings reported in Table 3 (cardiovascular effects were observed in every year post disaster, while mental health effects were reported during the first 2 years post disaster).

\section{RESULTS}

Statistical group comparisons (analysis of variance for continuous variables and chi-square tests for categorical variables) did not yield statistically significant differences between parents of burned children $(n=273)$, parents of unburned children $(n=199)$, and community controls $(n=1756)$ with regard to gender and insurance type (Table 1). Parents of burned children (mean age 45.7, S.D. 4.2) were significantly older than parents of unburned children (mean age 46.7, S.D. 5.0).

\section{[TABLE 1]}

Table 2 provides the number and percentage of parents with mental, musculoskeletal, respiratory, gastrointestinal, and dermatological health problems. Considering mental health problems, parents of victims with burns showed larger increases from the prefire baseline than parents of victims without burns, with the increase being the strongest in the first year following the fire, the year 2001. Furthermore, cardiovascular health problems had increased in all three cohorts in the course of the 4-year follow-up 
T. Dorn; J.C. Yzermans; P.M. Spreeuwenberg; J. van der Zee. Physical and mental health problems in parents of adolescents with burns--a controlled, longitudinal study. Journalof psychosomatic Research 2007 , vol. 63, nr. 4 p. 381-389.

period. Although there were differences at baseline between groups, the strongest deviations from the baseline were seen in parents of victims with burns, followed by parents of victims without burns.

\section{[TABLE 2]}

Table 3 presents the results of the multivariate analyses. The provided ORs indicate whether the likelihood for presenting a health problem has increased or decreased during the year in question. The confidence intervals indicate whether the finding is statistically significant or not (significant ORs are printed in bold). In parents of children with burns, significant postfire increases were mainly observed in two areas, cardiovascular and mental health.

\section{[TABLE 3]}

In the years 2001 (OR, 2.67; 95\% CI, 1.61-4.44), 2002 (OR, 4.87; 95\% CI, 2.96-8.00), 2003 (OR, 5.47; 95\% CI, 3.33-8.97) and 2004 (OR, 4.20; 95\% CI, 2.55-6.92), the likelihood for presenting a cardiovascular health problem was significantly increased in parents of children with burns, when compared to the year pre fire. Significant postfire increases in cardiovascular health problems were also observed in parents of victims without burns and in controls. Between-group comparisons demonstrated that the postfire increase of cardiovascular health problems observed in parents of burn victims was significantly larger than in parents of unburned victims during the year 2002 and 2003. In 2002, for example, the OR for parents of victims with burns was 4.87 (95\% CI, 2.96-8.00). In parents of victims without burns, it was 2.08 (95\% CI, 1.23-3.51). These two ORs differ significantly from each other (Table 3, marked by ${ }^{\mathrm{a}}$ ), meaning that the postfire increase in cardiovascular problems observed in parents of burn victims was significantly larger than in parents of victims without burns.

With regard to mental health problems, the analysis showed that after the fire, parents of burn victims were more likely to present mental problems during the year 2001 (OR, 5.87; 95\% CI, 3.73-9.24) and 2002 (OR, 2.86; 95\% CI, 1.80-4.55; Table 3). When compared to community controls, parents of burn victims demonstrated larger postfire increases in mental health problems in every year of the 4-year follow-up period (marked by ${ }^{c}$ ). When compared to parents of victims without burns, parents of burn victims demonstrated larger postfire increases in mental health problems in 2001, 2002, and 2004, but not in 2003 (marked by ${ }^{\mathrm{a}}$ ).

Since most changes have been observed in the mental and cardiovascular health domains, additionally, predictors for these problems in parents of burn victims were examined (Table 4 and Table 5). As already demonstrated in the previous analyses, the proportion of parents of children with burns who presented with mental health problems had significantly increased compared to the prefire baseline (OR, 4.82; 95\% CI, 2.09-11.10; Table 4). Also, the proportion was lower in parents who were enrolled with practice 1 compared to the reference (practice 3) (OR, 0.13; 95\% CI, 0.03-0.58). As the interaction terms demonstrate, the postfire increase in mothers was much stronger than the postfire increase in fathers (OR 9.87; 95\% CI 3.93-24.84). Finally, the total burn surface area of the child significantly predicted if parents presented a mental health problem or not (OR, 1.05; 95\% CI, 1.02-1.08). In other words, the larger the burn, the higher the likelihood of parents presenting a mental health problem during the first 2 years post fire.

\section{[TABLE 4]}

\section{[TABLE 5]}

In order to make sure that these associations between gender and mental health problems are specific to parents of burn victims, additional analyses were performed for the cohort of community controls (not in table). In this group, independent of the time of measurement, women were also more likely to present with mental health problems (OR, 2.03; 95\% CI, 1.47-2.81; not in table). In contrast to parents of burn victims, the interaction term (post fire*female gender) indicated that the postfire increase was larger in male controls than in female controls (OR, 0.67; 95\% CI, 0.45-1.00; not in table) and not vice versa, as it was the case in parents of burn victims. The analysis also demonstrated the same practice effect as in the analysis of parents of children with burns (OR, 0.43; 95\% CI, 0.32-0.59; not in table).

Finally, the likelihood of presenting with a cardiovascular health problem during the 4 years of follow-up was investigated in parents of burn victims (Table 5). Here, we also observed a significant postfire increase 
in cardiovascular health problems (OR, 118.27; 95\% CI, 50.28-278.20). The effect is large in size since the prefire period is only 1 year compared to the postfire period examined here, which is 4 years (the longer the observation period, the higher the likelihood of presenting with the problem). There were no significant differences regarding gender, insurance type, age, or practice in this analysis. Two interaction terms were significant, however. First, mothers of burned children were more likely to present with a cardiovascular problem than fathers (OR, 6.35; 95\% CI, 2.09-19.28). Second, public health insurance significantly predicted the likelihood of presenting such a problem during follow-up (OR, 9.43; 95\% CI, 2.93-30.37). Since in this study insurance type is determined by family income, it can be concluded that parents of children with burns from a lower socioeconomic background were more vulnerable than parents of children with burns from a higher socioeconomic background.

As in mental health problems, the control group was examined in an additional analysis (not in table). The interaction terms, which indicate that an increase is significantly larger in one group when compared to the reference group, demonstrated that female controls and controls with public insurance were not more likely to present with cardiovascular problems during the postfire period when compared to male controls or controls with private insurance [post fire*female gender (OR, 1.11; 95\% CI, 0.79-1.57) and post fire*public health insurance (OR, 0.90; 95\% CI, 0.63-1.27), respectively; not in table].

\section{DISCUSSION}

This study shows that the health of parents of adolescents with burns differed from the health of other parents in two main areas: cardiovascular and mental health problems. Whereas mental health problems were most pressing during the first and second year after burn injuries had been inflicted, cardiovascular health problems appeared to be at elevated levels in later years. As expected, the largest increases were observed in parents of victims with burns, followed by parents of victims without burns, and controls.

Despite the fact that we examined several physical health outcomes, no substantial effects on health problems in the gastrointestinal, respiratory, musculoskeletal, or dermatological domains were found. Although evidence linking cardiovascular disease and exposure to psychological trauma is strong and has been found consistently across different populations and stressful events [30], it is difficult to determine why the physical effects mainly emerge in the cardiovascular domain. Cardiovascular diseases develop as a result of a number of risk factors, such as smoking, excessive drinking, high blood pressure and cholesterol, obesity, lack of physical activity, and an unhealthy diet. It has been suggested that behaviors such as smoking and alcohol and drug use can operate as coping strategies, which help to reduce feelings of stress in the short term but damage health in the long term [31]. Healthy lifestyles may thus deteriorate as a consequence of life stress and, in turn, increase the cardiovascular disease risk.

In addition, the physiological stress response in humans includes an increase in force to the vessel wall, with blood pressure peaks, vasoconstriction, and exaggerated coagulation activation [32] and [33]. In this case, wear and tear to the cardiovascular system may occur. The concept of "allostatic load" has been coined to describe the cumulative physiological toll exacted on the body over time by efforts to adapt to life experiences [34]. High allostatic load has been associated with declines in physical functioning and with an increased risk for cardiovascular disease [35] and [36]. In addition, there is an abundant literature to demonstrate that the risk of coronary artery disease is elevated in subjects with depression, anxiety, exhaustion, worry, anger, or hostility - a range of emotions one would also expect in the parents included in this study [37], [38], [39] and [40]. To possibly corroborate the psychosocial mediators, which link the experience of parenting a child with burns to adverse health outcomes, more research is warranted, however.

Another point of interest concerned the question as to which factors are related to mental and cardiovascular health problems in parents of burn victims. Female gender and a high burn surface area of the child predicted mental health problems in parents of burn patients, whereas cardiovascular health problems were associated with parental public health insurance and female gender, but not with the burn size of the child. The gender effect for mental and cardiovascular health problems observed in the current study is in line with previous findings [41]. Traditionally, women have been assigned the role of caregiver, a role that may lead to increased stress levels. Norris et al. [42] noted in their review of disaster studies that being a parent, especially a mother, was associated with higher distress. In addition, in the Netherlands, public health insurance is indicative for lower incomes. Lower socioeconomic status, in turn, is generally 
T. Dorn; J.C. Yzermans; P.M. Spreeuwenberg; J. van der Zee.

Physical and mental health problems in parents of adolescents with burns--a controlled, longitudinal study. Journalof psychosomatic Research 2007 , vol. 63, nr. 4 p. 381-389.

considered a risk factor for ill health, and this association has also been reported for cardiovascular health [25] and [43].

\section{Strengths, weaknesses, and limitations}

Our study has several strengths. First of all, physical health effects are generally under-researched outcomes when it comes to caregivers of medically fragile children. In addition, so far, no studies existed on the physical health of parents of children with burns. The present study has therefore made a contribution to a knowledge base, which is still rather small. Furthermore, from a methodological point of view, the design of the study was strong. We prospectively examined changes in health problems within groups (changes over time) and changes in health problems between different groups of parents. The observation period was 4 years, and baseline data were available for 1 year pre event. The estimates of health problems are reliable since all health problems were physician-verified and are not biased by selfreport. Also, the study is population-based. Since the research was based on preexisting electronic registries, selection and recall bias are ruled out. This is an important advantage, since many samples included in previous research were drawn from specialty centers and tend to exclude those parents who are well in spite of the burn incident. Also, fathers are often underrepresented in comparable studies - a problem not present in the current research. It can thus be assumed that these findings are generally representative of parents of adolescents with burns.

In spite of these strengths, the study has some weaknesses and limitations. First, we were not able to measure other variables, which also might negatively affect health. Examples are unhealthy lifestyles and other negative life-events. Second, it should be noted that some parents included in the cohort of community controls may have been indirectly affected by the fire as they could belong to the extended families of the victims. This would lead to an underestimation of the differences found between groups, however, and not to an overestimation of effects. Third, as already mentioned, the study was based on electronic medical records, and mediating psychological variables were not assessed. These variables would help to shed more light on the underlying processes that lead to adverse physical health outcomes. Fourth, not every parent who experiences emotional problems may also seek help from a FP. Our study therefore predominantly assesses physician utilization for mental health and not the actual prevalence of these problems. Finally, while a broad range of health outcomes was assessed simultaneously in this chapter, health problems have not yet been considered at a more fine-grained level. Other study results, for example, indicate that hypertension may be the most important disorder which contributes to the decrements in cardiovascular health found here at a more general level [44].

In conclusion, some practical implications should be noted. First, it is important to meet parental mental health needs and to guarantee appropriate monitoring of health in general and cardiovascular problems in particular. Second, it should not be forgotten that from a system's point of view, parents and children are interrelated [45] and [46] and that the well-being of the parent may also affect the outcomes of the child. Interestingly, in most studies of pediatric burn survivors, burn severity did not predict psychosocial adjustment of the child, but good family relationships did [47]. In the interest of both the child and the parents, interventions should thus be directed at the family as a system.

\section{ACKNOWLEDGMENTS}

We thank all Volendam FPs for the provision of the data and Petra ten Veen for the management of the database.

\section{TABLES}

Table 1

Background characteristics of parents of victims with burns, parents of victims without burns, and community controls

\begin{tabular}{|c|c|c|c|c|c|}
\hline & Parents of burned victims & Parents of unburned victims & Controls & $\mathrm{Col}$ & Comparison \\
\hline & $n=273$ & $n=199$ & $n=1.756$ & "burned" and "unburned" & "unburned" and controls \\
\hline \multicolumn{6}{|l|}{ Gender } \\
\hline Men $(\%)$ & $129(47.3)$ & $96(48.2)$ & $841(47.9)$ & NS & NS \\
\hline Women $(\%)$ & $144(52.7)$ & $103(51.8)$ & $915(52.1)$ & & \\
\hline Age [mean (S.D.)] & $45.7(4.2)$ & $46.7(5.0)$ & $46.7(4.8)$ & $*$ & NS \\
\hline \multicolumn{6}{|l|}{ Insurance } \\
\hline Private $(\%)$ & $108(39.6)$ & $79(39.7)$ & $773(44.0)$ & NS & NS \\
\hline Public (\%) & $165(60.4)$ & $120(60.3)$ & $983(56.0)$ & & \\
\hline
\end{tabular}

* Significant at $P<.05 ; \mathrm{NS}$, nonsignificant. 
T. Dorn; J.C. Yzermans; P.M. Spreeuwenberg; J. van der Zee.

Physical and mental health problems in parents of adolescents with burns--a controlled, longitudinal study. Journalof psychosomatic Research 2007 , vol. 63, nr. 4 p. 381-389.

Table 2

Number of parents $(\%)$ with health problem

\begin{tabular}{|c|c|c|c|c|c|}
\hline & 2000 (pre fire) & 2001 (post fire) & 2002 (post fire) & 2003 (post fire) & 2004 (post fire) \\
\hline \multicolumn{6}{|l|}{ Cardiovascular } \\
\hline Parents, burned & $29(10.6)$ & $47(17.2)$ & $63(23.3)$ & $63(23.3)$ & $58(21.6)$ \\
\hline Parents, unburned & $32(16.1)$ & $39(19.6)$ & $41(20.7)$ & $38(19.2)$ & $45(22.7)$ \\
\hline Controls & $231(13.2)$ & $258(14.8)$ & $271(15.7)$ & $277(16.2)$ & $283(16.6)$ \\
\hline \multicolumn{6}{|l|}{ Musculoskeletal } \\
\hline Parents, burned & $117(42.9)$ & $127(46.5)$ & $132(48.9)$ & $129(47.8)$ & $136(50.6)$ \\
\hline Parents, unburned & $97(48.7)$ & $91(45.7)$ & $111(56.1)$ & $99(50.0)$ & $111(56.1)$ \\
\hline Controls & $719(40.9)$ & $726(41.5)$ & $716(41.6)$ & $721(42.2)$ & $744(43.6)$ \\
\hline \multicolumn{6}{|l|}{ Gastrointestinal } \\
\hline Parents, burned & $43(15.8)$ & 37 (13.6) & $38(14.1)$ & $48(17.8)$ & $51(19.0)$ \\
\hline Parents, unburned & $32(16.1)$ & $42(21.1)$ & $38(19.2)$ & $37(18.7)$ & $25(12.6)$ \\
\hline Controls & $281(16.0)$ & $264(15.1)$ & $235(13.7)$ & $235(13.8)$ & $258(15.1)$ \\
\hline \multicolumn{6}{|l|}{ Dermatological } \\
\hline Parents, burned & $76(27.8)$ & $77(28.2)$ & $70(25.9)$ & $88(32.6)$ & $83(30.9)$ \\
\hline Parents, unburned & $61(30.7)$ & $73(36.7)$ & $69(34.8)$ & $56(28.3)$ & $69(34.8)$ \\
\hline Controls & $459(26.1)$ & $455(26.0)$ & $456(26.5)$ & 489 (28.6) & $502(29.4)$ \\
\hline \multicolumn{6}{|l|}{ Respiratory } \\
\hline Parents, burned & $80(29.3)$ & $89(32.6)$ & $95(35.2)$ & $79(29.3)$ & $64(23.8)$ \\
\hline Parents, unburned & $61(30.7)$ & $51(25.6)$ & $75(37.9)$ & $63(31.8)$ & $57(28.8)$ \\
\hline Controls & $469(26.7)$ & $492(28.1)$ & $468(27.2)$ & 449 (26.3) & $423(24.8)$ \\
\hline \multicolumn{6}{|l|}{ Mental } \\
\hline Parents, burned & $26(9.5)$ & $70(25.6)$ & $49(18.1)$ & $31(11.5)$ & $32(11.9)$ \\
\hline Parents, unburned & $26(13.1)$ & $31(15.6)$ & $11(5.6)$ & $25(12.6)$ & $19(9.6)$ \\
\hline Controls & $202(11.5)$ & 208 (11.9) & $190(11.0)$ & $164(9.6)$ & $171(10.0)$ \\
\hline
\end{tabular}

Date of the fire: January 1, 2001.

Table 3

Logistic regression analyses with health problem $(\mathrm{yes}=1 / \mathrm{no}=0)$ as dependent variable

\begin{tabular}{|c|c|c|c|c|c|c|c|c|c|c|c|c|c|c|c|c|c|c|}
\hline \multirow{3}{*}{ Parents, burned } & \multicolumn{3}{|c|}{ Cardiovascular } & \multicolumn{3}{|c|}{ Musculoskeletal } & \multicolumn{3}{|c|}{ Gastrointestinal } & \multicolumn{3}{|c|}{ Dermatological } & \multicolumn{3}{|c|}{ Respiratory } & \multicolumn{3}{|c|}{ Mental } \\
\hline & OR & \multicolumn{2}{|c|}{$95 \% \mathrm{CI}$} & OR & \multicolumn{2}{|c|}{$95 \% \mathrm{CI}$} & OR & \multicolumn{2}{|c|}{$95 \% \mathrm{CI}$} & OR & \multicolumn{2}{|c|}{$95 \% \mathrm{CI}$} & OR & \multicolumn{2}{|c|}{$95 \% \mathrm{CI}$} & OR & \multicolumn{2}{|c|}{$95 \% \mathrm{CI}$} \\
\hline & 2.67 & 1.61 & 4.44 & 1.21 & 0.86 & 1.71 & $0.80^{\mathrm{a}}$ & 0.50 & 1.26 & 1.02 & 0.71 & 1.48 & 1.23 & 0.85 & 1.79 & $5.87^{\mathrm{a}}$ & 3.73 & 9.24 \\
\hline Change 2002 & $4.87^{\mathrm{a}}$ & 2.96 & 8.00 & 1.36 & 0.96 & 1.92 & 0.84 & 0.53 & 1.33 & 0.89 & 0.61 & 1.29 & 1.43 & 0.99 & 2.06 & $2.86^{\mathrm{a}}$ & 1.80 & 4.55 \\
\hline Change 2003 & $5.47^{\mathrm{a}}$ & 3.33 & 8.97 & 1.28 & 0.91 & 1.81 & 1.21 & 0.78 & 1.87 & 1.29 & 0.90 & 1.86 & 0.99 & 0.68 & 1.44 & 1.31 & 0.80 & 2.15 \\
\hline Change 2004 & 4.20 & 2.55 & 6.92 & 1.49 & 1.05 & 2.10 & 1.35 & 0.87 & 2.08 & 1.17 & 0.81 & 1.69 & 0.68 & 0.46 & 1.01 & $1.38^{\mathrm{a}}$ & 0.84 & 2.25 \\
\hline \multicolumn{19}{|c|}{ Parents, unburned } \\
\hline Change 2001 & 1.86 & 1.09 & 3.15 & 0.85 & 0.57 & 1.28 & $1.59^{\mathrm{b}}$ & 0.96 & 2.63 & 1.37 & 0.91 & 2.07 & 0.71 & 0.45 & 1.11 & 1.35 & 0.80 & 2.28 \\
\hline Change 2002 & 2.08 & 1.23 & 3.51 & 1.48 & 0.98 & 2.23 & 1.37 & 0.82 & 2.29 & 1.25 & 0.82 & 1.89 & 1.59 & 1.03 & 2.45 & $0.29^{\mathrm{b}}$ & 0.15 & 0.56 \\
\hline Change 2003 & 1.66 & 0.97 & 2.83 & 1.07 & 0.72 & 1.61 & 1.31 & 0.78 & 2.20 & 0.87 & 0.57 & 1.34 & 1.09 & 0.70 & 1.69 & 0.94 & 0.55 & 1.62 \\
\hline Change 2004 & 2.70 & 1.61 & 4.54 & 1.48 & 0.98 & 2.23 & 0.70 & 0.40 & 1.23 & 1.25 & 0.82 & 1.89 & 0.89 & 0.57 & 1.40 & 0.61 & 0.35 & 1.09 \\
\hline \multicolumn{19}{|l|}{ Controls } \\
\hline Change 2001 & $1.30^{\mathrm{c}}$ & 1.07 & 1.5 & .03 & 0.90 & 1.1 & 0.91 & 0.76 & 1.0 & 0.99 & 0.85 & 1. & 1.11 & 0.95 & 1.29 & $1.06^{\mathrm{c}}$ & 0.87 & 1.28 \\
\hline Change 2002 & $1.46^{\mathrm{c}}$ & 1.21 & 1.76 & 1.03 & 0.89 & 1.18 & 0.78 & 0.65 & 0.93 & 1.02 & 0.87 & 1.18 & 1.03 & 0.88 & 1.20 & $0.92^{\mathrm{c}}$ & 0.76 & 1.13 \\
\hline Change 2003 & $1.41^{\mathrm{c}}$ & 1.16 & 1.70 & 1.06 & 0.92 & 1.21 & 0.79 & 0.66 & 0.95 & 1.15 & 0.99 & 1.34 & 0.96 & 0.82 & 1.12 & $0.75^{\mathrm{c}}$ & 0.61 & 0.92 \\
\hline Change 2004 & $1.50^{\mathrm{c}}$ & 1.25 & 1.82 & 1.14 & 0.99 & 1.31 & 0.91 & 0.76 & 1.09 & 1.21 & 1.04 & 1.40 & 0.86 & 0.74 & 1.01 & $0.80^{\mathrm{c}}$ & 0.66 & 0.98 \\
\hline
\end{tabular}

Date of the fire: January 1, 2001. Change 2001, 2002, 2003, and 2004 indicate change per year when compared to the year pre fire (year 2000). ORs are printed in bold (alpha $=5 \%$ ). ORs above 1 indicate an increase in likelihood; ORs below 1 indicate a decrease in likelihood for presenting the health problem. All coefficients are adjusted for the influence of age, family practice, gender, and insurance type.

a Comparison "parents, burned" vs. "parents, unburned"; significant at alpha $=5 \%$.

b Comparison "parents, unburned" vs. "controls"; significant at alpha $=5 \%$.

c Comparison "controls" vs. "parents, burned"; significant at alpha $=5 \%$. 
T. Dorn; J.C. Yzermans; P.M. Spreeuwenberg; J. van der Zee.

Physical and mental health problems in parents of adolescents with burns--a controlled, longitudinal study Journalof psychosomatic Research 2007 , vol. 63, nr. 4 p. 381-389.

Table 4

Parents of children with burns: predictors of mental health problems during the first 2 years post fire (logistic regression)

\begin{tabular}{lllr}
\hline & Mental & \\
\cline { 2 - 4 } & OR & \multicolumn{2}{c}{$95 \%$ CI } \\
\hline Post fire (reference: pre fire) & $\mathbf{4 . 8 2}$ & $\mathbf{2 . 0 9}$ & $\mathbf{1 1 . 1 0}$ \\
Female gender (reference: male) & 0.55 & 0.17 & 1.83 \\
Age (years) & 1.02 & 0.90 & 1.16 \\
Public health insurance & 1.55 & 0.48 & 5.08 \\
$\quad$ (reference: private) & & & \\
$\quad$ Two children affected & 1.34 & 0.27 & 6.61 \\
$\quad$ (reference: one child affected) & & & \\
Total burn surface area of child (\%) & 1.01 & 0.97 & 1.04 \\
Enrolled at practice 1 & $\mathbf{0 . 1 3}$ & $\mathbf{0 . 0 3}$ & $\mathbf{0 . 5 8}$ \\
$\quad$ (reference: practice 3) & & & \\
Enrolled at practice 2 & 0.43 & 0.12 & 1.61 \\
$\quad$ (reference: practice 3) & & & \\
Post-fire*female gender & $\mathbf{9 . 8 7}$ & $\mathbf{3 . 9 3}$ & $\mathbf{2 4 . 8 4}$ \\
Post-fire*public health insurance & 1.23 & 0.50 & 3.06 \\
Post-fire*two children affected & 0.99 & 0.30 & 3.30 \\
Post-fire*total burn surface area of child & $\mathbf{1 . 0 5}$ & $\mathbf{1 . 0 2}$ & $\mathbf{1 . 0 8}$ \\
\hline
\end{tabular}

Table 5

Parents of children with burns: predictors of cardiovascular health problems during the first 4 years post fire (logistic regression)

\begin{tabular}{lrrr}
\hline & \multicolumn{3}{c}{ Cardiovascular } \\
\cline { 2 - 4 } & \multicolumn{1}{c}{ OR } & \multicolumn{2}{c}{$95 \%$ CI } \\
\hline Post fire (reference: pre fire) & $\mathbf{1 1 8 . 2 7}$ & $\mathbf{5 0 . 2 8}$ & $\mathbf{2 7 8 . 2 0}$ \\
Female gender (reference: male) & 0.60 & 0.14 & 2.64 \\
Age (years) & 1.05 & 0.88 & 1.25 \\
Public health insurance & 0.70 & 0.14 & 3.60 \\
$\quad$ (reference: private) & & & \\
Two children affected & 0.47 & 0.04 & 5.34 \\
$\quad$ (reference: one child affected) & & & \\
Total burn surface area of child (\%) & 1.02 & 0.98 & 1.07 \\
Enrolled at practice 1 & 0.31 & 0.04 & 2.55 \\
$\quad$ (reference: practice 3) & & & \\
Enrolled at practice 2 & 1.17 & 0.18 & 7.72 \\
$\quad$ (reference: practice 3) & & \multicolumn{2}{c}{} \\
Post fire*Female gender & $\mathbf{6 . 3 5}$ & $\mathbf{2 . 0 9}$ & $\mathbf{1 9 . 2 8}$ \\
Post fire*public health insurance & $\mathbf{9 . 4 3}$ & $\mathbf{2 . 9 3}$ & $\mathbf{3 0 . 3 7}$ \\
Post fire*two children affected & 0.95 & 0.15 & 6.14 \\
Post fire*total burn surface area of child & 0.97 & 0.95 & 1.00 \\
\hline
\end{tabular}




\section{REFERENCES}

[1] JH Barlow and DR Ellard, The psychosocial well-being of children with chronic disease, their parents and siblings: an overview of the research evidence base, Child Care Health Dev 32 (2006), pp. 19-31.

[2] JC Brehaut, DE Kohen, P Raina, SD Walter, DJ Russell and M Swinton et al., The health of primary caregivers of children with cerebral palsy: how does it compare with that of other Canadian caregivers?, Pediatrics 114 (2004), pp. e182-e191.

[3] P Raina, M O'Donnell, P Rosenbaum, J Brehaut, SD Walter and D Russell et al., The health and wellbeing of caregivers of children with cerebral palsy, Pediatrics 115 (2005), pp. e626-e636.

[4] HC Tong, G Kandala, AJ Haig, VS Nelson, KS Yamakawa and KY Shin, Physical functioning in female caregivers of children with physical disabilities compared with female caregivers of children with a chronic medical condition, Arch Pediatr Adolesc Med 156 (2002), pp. 1138-1142.

[5] HC Tong, AJ Haig, VS Nelson, KS Yamakawa, G Kandala and KY Shin, Low back pain in adult female caregivers of children with physical disabilities, Arch Pediatr Adolesc Med 157 (2003), pp. 1128-1133.

[6] K Midence, C McManus, P Fuggle and S Davies, Psychological adjustment and family functioning in a group of British children with sickle cell disease: preliminary empirical findings and a meta-analysis, $\mathrm{Br} \mathrm{J}$ Clin Psychol 35 (Pt 3) (1996), pp. 439-450.

[7] MA Grootenhuis and BF Last, Adjustment and coping by parents of children with cancer: a review of the literature, Support Care Cancer 5 (1997), pp. 466-484.

[8] K Vedhara, MP McDermott, TG Evans, JJ Treanor, S Plummer and D Tallon et al., Chronic stress in nonelderly caregivers: psychological, endocrine and immune implications, J Psychosom Res 53 (2002), pp. 1153-1161.

[9] K Vedhara, N Shanks, S Anderson and S Lightman, The role of stressors and psychosocial variables in the stress process: a study of chronic caregiver stress, Psychosom Med 62 (2000), pp. 374-385.

[10] PP Vitaliano, J Zhang and JM Scanlan, Is caregiving hazardous to one's physical health? A metaanalysis, Psychol Bull 129 (2003), pp. 946-972.

[11] JK Kiecolt-Glaser, JR Dura, CE Speicher, OJ Trask and R Glaser, Spousal caregivers of dementia victims: longitudinal changes in immunity and health, Psychosom Med 53 (1991), pp. 345-362.

[12] P Blakeney, P Moore, L Broemeling, R Hunt, DN Herndon and M Robson, Parental stress as a cause and effect of pediatric burn injury, J Burn Care Rehabil 14 (1993), pp. 73-79.

[13] KJ Tarnowski and RT Brown, Burn injuries. In: AJ Goreczny and M Hersen, Editors, Handbook of pediatric and adolescent health psychology, Allyn and Bacon, Boston (1999), pp. 115-126.

[14] J Shelby, J Sullivan, M Groussman, R Gray and J Saffle, Severe burn injury: effects on psychologic and immunologic function in noninjured close relatives, J Burn Care Rehabil 13 (1992), pp. 58-63.

[15] LP Rizzone, FJ Stoddard, JM Murphy and LJ Kruger, Posttraumatic stress disorder in mothers of children and adolescents with burns, J Burn Care Rehabil 15 (1994), pp. 158-163.

[16] J LeDoux, WJ Meyer, PE Blakeney and DN Herndon, Relationship between parental emotional states, family environment and the behavioural adjustment of pediatric burn survivors, Burns 24 (1998), pp. 425432.

[17] E Hall, G Saxe, F Stoddard, J Kaplow, K Koenen and N Chawla et al., Posttraumatic stress symptoms in parents of children with acute burns, J Pediatr Psychol 31 (2006), pp. 403-412.

[18] I Fukunishi, Posttraumatic stress symptoms and depression in mothers of children with severe burn injuries, Psychol Rep 83 (1998), pp. 331-335.

[19] L Kent, H King and R Cochrane, Maternal and child psychological sequelae in paediatric burn injuries, Burns 26 (2000), pp. 317-322.

[20] SA Mason, Young, scarred children and their mothers-a short-term investigation into the practical, psychological and social implications of thermal injury to the preschool child. Part I: implications for the mother, Burns 19 (1993), pp. 495-500.

[21] Y El Hamaoui, S Yaalaoui, K Chihabeddine, E Boukind and D Moussaoui, Depression in mothers of burned children, Arch Womens Ment Health 9 (2006), pp. 117-119.

[22] WJ Meyer, P Blakeney, P Moore, L Murphy, M Robson and D Herndon, Parental well-being and behavioral adjustment of pediatric survivors of burns, J Burn Care Rehabil 15 (1994), pp. 62-68.

[23] L Welling, SM van Harten, P Patka, JJ Bierens, M Boers and JS Luitse et al., The cafe fire on New Year's Eve in Volendam, the Netherlands: description of events, Burns 31 (2005), pp. 548-554.

[24] CR Figley, Burnout in families: the systemic costs of caring, CRC Press, Boca Raton (Fla) (1998).

[25] SE Taylor, RL Repetti and T Seeman, Health psychology: what is an unhealthy environment and how does it get under the skin?, Annu Rev Psychol 48 (1997), pp. 411-447.

[26] WG Boerma, ZJ van der and DM Fleming, Service profiles of general practitioners in Europe.

European GP Task Profile Study, Br J Gen Pract 47 (1997), pp. 481-486.

[27] M Wood, H Lamberts, JS Meijer and IM Hofmans-Okkes, The conversion between ICPC and ICD-10. Requirements for a family of classification systems in the next decade, Fam Pract 9 (1992), pp. 340-348. 
T. Dorn; J.C. Yzermans; P.M. Spreeuwenberg; J. van der Zee.

Physical and mental health problems in parents of adolescents with burns--a controlled, longitudinal study. Journalof psychosomatic Research 2007 , vol. 63, nr. 4 p. 381-389.

[28] IM Hofmans-Okkes and H Lamberts, The International Classification of Primary Care (ICPC): new applications in research and computer-based patient records in family practice, Fam Pract 13 (1996), pp. 294-302.

[29] TB Snijder and R Bosker, Multilevel analysis: an introduction to basic and advanced multilevel modeling, Sage, Thousand Oaks (CA) (1999).

[30] JA Boscarino, Posttraumatic stress disorder and physical illness: results from clinical and epidemiologic studies, Ann N Y Acad Sci 1032 (2004), pp. 141-153.

[31] PP Schnurr and BL Green, Understanding relationships among trauma, posttraumatic stress disorder, and health outcomes. In: BL Green and PP Schnurr, Editors, Trauma and health: physical health consequences of exposure to extreme stress, American Psychological Association, Washington, DC, US (2004), pp. 247-275.

[32] WB Cannon and WL Mendenhall, Factors affecting the coagulation time of blood: IV. The hastening of coagulation in pain and emotional excitement, Am J Physiol 34 (1914), pp. 251-261.

[33] BS McEwen, The neurobiology of stress: from serendipity to clinical relevance, Brain Res 886 (2000), pp. 172-189.

[34] BS McEwen and E Stellar, Stress and the individual: mechanisms leading to disease, Arch Intern Med 153 (1993), pp. 2093-2101.

[35] TE Seeman, BH Singer, JW Rowe, RI Horwitz and BS McEwen, Price of adaptation-allostatic load and its health consequences. MacArthur studies of successful aging, Arch Intern Med 157 (1997), pp. 22592268.

[36] PH Black and LD Garbutt, Stress, inflammation and cardiovascular disease, J Psychosom Res 52 (2002), pp. 1-23.

[37] AC Phillips, D Carroll, C Ring, H Sweeting and P West, Life events and acute cardiovascular reactions to mental stress: a cohort study, Psychosom Med 67 (2005), pp. 384-392.

[38] TG Pickering, Mental stress as a causal factor in the development of hypertension and cardiovascular disease, Curr Hypertens Rep 3 (2001), pp. 249-254.

[39] A Rozanski, JA Blumenthal and J Kaplan, Impact of psychological factors on the pathogenesis of cardiovascular disease and implications for therapy, Circulation 99 (1999), pp. 2192-2217.

[40] JF Brosschot, W Gerin and JF Thayer, The perseverative cognition hypothesis: a review of worry, prolonged stress-related physiological activation, and health, J Psychosom Res 60 (2006), pp. 113-124.

[41] AJ Dirkzwager, L Grievink, PG van der Velden and CJ Yzermans, Risk factors for psychological and physical health problems after a man-made disaster. Prospective study, $\mathrm{Br} \mathrm{J}$ Psychiatry 189 (2006), pp. 144-149.

[42] FH Norris, MJ Friedman and PJ Watson, 60,000 disaster victims speak: Part II. Summary and implications of the disaster mental health research, Psychiatry 65 (2002), pp. 240-260.

[43] CJ Yzermans, GA Donker, JJ Kerssens, AJ Dirkzwager, RJ Soeteman and PM Ten Veen, Health problems of victims before and after disaster: a longitudinal study in general practice, Int J Epidemiol 34 (2005), pp. 810-819.

[44] T Dorn, CJ Yzermans, H Guijt and ZJ van der, Disaster-related stress as a prospective risk factor for hypertension in parents of adolescent fire victims, Am J Epidemiol 165 (2007), pp. 410-417.

[45] CR Figley, Burnout as systemic traumatic stress: a model for helping traumatized family members. In: CR Figley, Editor, The systemic costs of caring, CRC Press, Boca Raton (Fla) (1998), pp. 15-28.

[46] MF Barnes, Understanding the secondary traumatic stress of parents. In: CR Figley, Editor, The systemic costs of caring, CRC Press, Boca Raton (Fla) (1998), pp. 75-89.

[47] MA Landolt, S Grubenmann and M Meuli, Family impact greatest: predictors of quality of life and psychological adjustment in pediatric burn survivors, J Trauma 53 (2002), pp. 1146-1151. 